\title{
Anisotropic garnet from the Yamansu ore deposit, Xinjiang, China
}

\author{
Shoichi Kobayashi ${ }^{*}$, Ritsuro MiYaWAKI ${ }^{* *}$, Koichi Momma ${ }^{* *}$, Akiko FuJISAWA* \\ and Hiroaki KANEDA ${ }^{* * *}$ \\ "Department of Applied Science, Faculty of Science, Okayama University of Science, \\ 1-1 Ridai-cho, Kita-ku, Okayama 700-0005, Japan \\ **Department of Geology and Paleontology, National Museum of Nature and Science, \\ 4-1-1 Amakubo, Tsukuba, Ibaraki 305-0005, Japan \\ *** Department of Environmental Science, Faculty of Science, Toho University, \\ 2-2-1 Miyama, Funabashi, Chiba 274-8501, Japan
}

\begin{abstract}
An anisotropic garnet was found in skarn ores occurring in the Yamansu deposit, east part of Xinjiang, China. Optical birefringence of the anisotropic garnet varies from 0.001 to 0.004 . The chemical composition of the garnet essentially belongs to the grossular (Grs)-andradite (And) solid solution ranging from $\mathrm{Grs}_{35.3} \mathrm{And}_{60.1}$ to $\mathrm{Grs}_{55.8} \mathrm{And}_{38.5}$, with minor $(<8 \%)$ uvarovite, pyrope, almandine and spessartine constituent. Negative correlation was slightly observed between $\mathrm{Al}$ and $\mathrm{Fe}$ in the garnet. The absence of $\mathrm{OH}$ stretching vibration in IR spectrum suggests no substitution of $\left[\mathrm{SiO}_{4}\right]$ with tetrahedral $\left[(\mathrm{OH})_{4}\right]$ in the garnet.

A refinement of the crystal structure, $I \overline{1}(R=0.0435)$, showed no significant drifts of atoms from the ideal positions corresponding to the atomic positions in the $I a \overline{3} d$ cubic symmetry $(R=0.0544)$. The Al-Fe ordering was observed in the octahedral $M$ site, whereas the $\mathrm{Ca}-\mathrm{Fe}$ ordering in the dodecahedral site was negligible. The $\mathrm{Al}-\mathrm{Fe}$ ordering showed no symmetric distribution among the 8 octahedral $M$ sites, indicating the true symmetry of this garnet to be triclinic $I \bar{l}$.
\end{abstract}

Keywords: Anisotropic garnet, Chemistry, Crystal structure, Yamansu deposit, Xinjiang

\section{INTRODUCTION}

Garnet occurs in a wide variety of rocks, and shows great variation in chemical composition. It generally has the crystal structure of cubic symmetry described by space group $I a \overline{3} d$. Garnets found in the crust of the Earth are usually optically isotropic, consistent with their cubic symmetry, whereas some garnets are optically anisotropic suggesting non-cubic crystal structure. The relationship between optically anisotropic garnets and geological setting was summarized by Deer et al. (1982) and Hofmeister et al. (1998). Host occurrences are xenoliths of eclogite and ultramafic rock, vein in serpentinite, metamorphic rocks such as schist and hornfels, sedimentary rocks, pegmatite, skarn and so on. Anisotropic garnet has been reported from various localities such as representatively South Africa, USA (California, Alaska, Carolina and Utah), Siberia, Portugal, Mexico, Brazil, Japan and so on.

The inciting factor of the optical anisotropy in gar-

doi:10.2465/jmps. 120927

S. Kobayashi, kobayashi@das.ous.ac.jp Corresponding author nets has been attributed to causes of large scale twinning (Ingerson and Barksdale, 1943) and residual strain from lattice mismatch at compositional, twin, or grain boundary (Chase and Lefever, 1960; Lessing and Standish, 1973; Kitamura and Komatsu, 1978). Some mechanisms of ordering have been reported as the origin of the optical anisotropy in garnets; 1) ordering undetected rare earth elements substituting for $\mathrm{Ca}$ in the dodecahedral site (Blanc and Maisonneuve, 1973; Gaspar et al., 2008), 2) non-cubic distribution of $\mathrm{OH}$ groups due to the hydrogarnet constituent, in which $\left[\mathrm{SiO}_{4}\right]$ is substituted by $\left[(\mathrm{OH})_{4}\right]$ (Rossman and Aines, 1986), 3) partial ordering of $\mathrm{Ca}^{2+}$ and $\mathrm{Fe}^{2+}$ in the distorted dodecahedral sites and/or $\mathrm{Fe}^{3+}$ and $\mathrm{Al}^{3+}$ in the octahedral sites (Takéuchi et al., 1982; Akizuki, 1984; Allen and Buseck, 1988). Hofmeister et al. (1998) also proposed that the mismatch in size between $\mathrm{Ca}^{2+}$ and $\mathrm{Mg}^{2+}$ exacerbates retention of residual strain from study of forty anisotropic single-crystal garnets of quaternary system of pyralspite-grossular. (The name pyralspite is used a convenient abbreviation for garnet solid solutions within the pyrope-almandine-spessartine ternary.) 
Refinements of the crystal structure were often conducted for garnets. In the grossular-andradite solid solution series, optically anisotropic members have been known, and the refinements of their crystal structures (Takéuchi et al., 1982; Allen and Buseck, 1988; Kingma and Downs, 1989) have shown that they crystallize in orthorhombic $(F d d d)$ or triclinic $(I \overline{1})$.

The origin of the birefringence has been a matter of some debate. Shtukenberg et al. (2001) reported that the origin of anomalous birefringence in grandite garnets (the solid solution series between grossular and andradite endmembers) from skarns in Mali and Russia is stress birefringence and growth dissymmetrization for two groups, which are found to have fundamentally different anomalous optical properties: crystal with low $(<0.001)$ and high (0.001-0.015) values of birefringence. Shtukenberg et al. (2005) tried to summarize and generalize the information on the non-cubic ugrandite garnets (the solid solution series among uvarovite, grossular and andradite end-members) using data of the crystal structures for 15 samples refined by different authors (Takéuchi et al., 1982; Allen and Buseck, 1988; Kingma and Downs, 1989; Griffen et al., 1992; Shtukenberg et al., 2002). Shtukenberg et al. (2005) mentioned that the crystals with the value of anomalous birefringence $(>0.001)$ are normally characterized by partial ordering of octahedral cations, and reduced the symmetry to the orthorhombic space group $F d d d$ or even to the triclinic space group $I \overline{1}$. Moreover, according to the model calculations of the optical indicatrix in the frame of the point-dipole approximation, they showed that the ordering appears to be the main reason for the anomalous birefringence in the ugrandite garnets.

In this study, we examined the cation ordering in an anisotropic garnet intermediate in composition between grossular and andradite with a small amount of uvarovite and pyralspite composition from the Yamansu skarn deposit, Xinjiang, China.

\section{GEOLOGY}

The Xinjiang Uygur Autonomous Region is located in northwestern China, bordering on Mongolia, Russia, Kazakhstan, Kyrgyzstan, Tajikistan, Afghanistan and Pakistan (Fig. 1). Anisotropic garnet was obtained from the Yamansu ore deposit, which is located about $60 \mathrm{~km}$ south-southeast of Hami and about $480 \mathrm{~km}$ southeast of Urumqi in East Tianshan mountain area. The east Tianshan is defined as that part of the Tianshan mountain range located east of the Urumqi-Kuerle highway. It is bounded to the north by the Turpan-Hami basin, which is a part of the Junggar block, to south by the Aqikekuduke fault, which separates this northern belt of the Tianshan

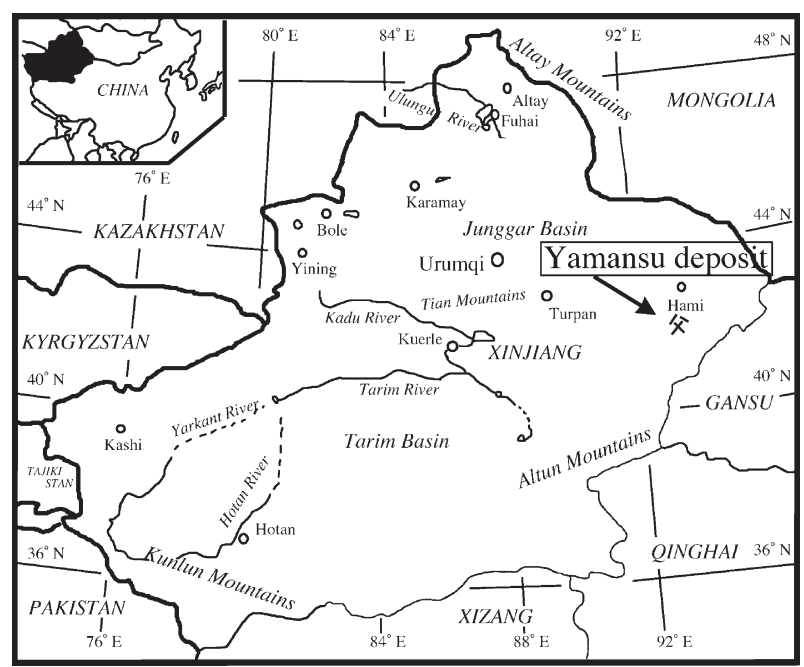

Figure 1. Location map of the Yamansu ore deposit, Xinjiang, China.

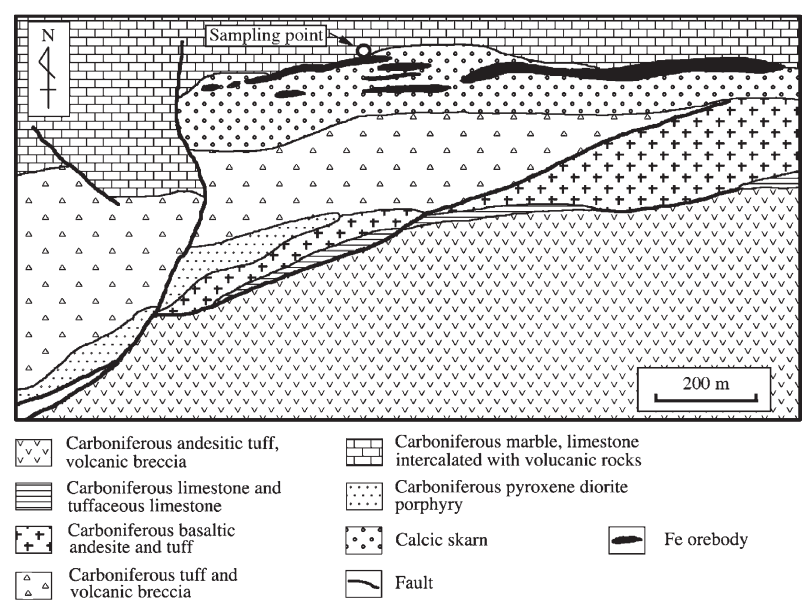

Figure 2. Simplified geological map of the Yamansu skarn deposit indicating the sampling point (modified from Mao et al., 2005).

from the so-called Middle Tianshan and to the east by the late Paleozoic Beishan rift (Mao et al., 2005). It is a region with an abundance of metallic mineral deposits. As a magnetite-bearing skarn deposit, the Yamansu ore deposit occurs within a $400 \mathrm{~km}$ long by $15 \mathrm{~km}$ wide corridor between the Aqishan-Yamansu and Aqikekuduke faults with the Bailingshan, Heijianshan, Chilongfeng, Hongyuntan, Aqishan, Heilongfeng, Shuangfengshan, and Shaquanzi deposits.

The Yamansu ore deposit is the largest and is hosted by the Lower Carboniferous submarine bimodal volcanic rocks and clastic rocks of the Yamansu Formation, mainly consisting of andesitic tuff, andesitic tuff breccia, limestone, potash-keratophyre, potash-porphyritic felsite, and felsite in the vicinity of iron-rich mineralization. The geological map is shown in Figure 2. The skarn developed at the contacts between limestone, which may be intercalat- 
ed with andesite breccia, tuff, agglomerate, basaltic andesite, and andesitic tuff, and rhyolitic tuff, and volcanic rocks that lack exposures of intrusive rock (Mao et al., 2005). Ore minerals at the Yamansu deposit are dominated by magnetite, hematite, pyrite, chalcocite, bornite, and chalcopyrite. The ore textures are disseminated, massive, and banded. Gangue minerals are composed mainly of garnet, diopside, actinolite, epidote, albite, and calcite. The anisotropic grossular-andradite series garnet was found in skarn ores with calcite and diopside.

\section{EXPERIMENTAL METHODS}

The crystals of anisotropic garnet from the Yamansu ore deposit were polished into thin section and examined with a petrographic microscope. Optical retardation (R) was estimated visually by comparison with a Michel-Levy interference color chart. Birefringence $(\delta)$ was calculated from

$$
\delta=n_{1}-n_{2}=\mathrm{R} / t
$$

where $n_{1}$ is the greater index of refraction, $n_{2}$ is the lesser one, and $t$ is the thickness (in nm) (e.g., Kerr, 1977). Thickness was measured with a digital micrometer.

Chemical analyses were carried out using an electron microprobe analyzer (JEOL JXA-8900R) at Okayama University of Science with wavelength-dispersion spectrometry (WDS) revealing the presence of each element in anisotropic garnet. The analytical conditions of WDS for each element are as follows: acceleration voltage $=15$ $\mathrm{kV}$, beam current $=12 \mathrm{nA}$, and beam diameter $=5 \mu \mathrm{m}$. The peak and backgrounds were measured for 10 and 5 seconds, respectively. Standard materials used were quartz $(\mathrm{Si})$, corundum $(\mathrm{Al})$, rutile $(\mathrm{Ti})$, eskolaite $(\mathrm{Cr})$, hematite $(\mathrm{Fe})$, periclase $(\mathrm{Mg})$, manganosite $(\mathrm{Mn})$, pentlandite $(\mathrm{Ni})$, wollastonite $(\mathrm{Ca})$, jadeite $(\mathrm{Na})$, and adularia $(\mathrm{K})$. The ZAF method was used for corrections. The elementdistribution maps of $\mathrm{Si} K \alpha, \mathrm{Ca} K \alpha, \mathrm{A} 1 K \alpha, \mathrm{Cr} K \alpha$, $\mathrm{Ti} K \alpha$, $\mathrm{Mn} K \alpha$ and $\mathrm{Fe} K \alpha$ in the anisotropic garnet, and composition images were obtained using a scanning electron microscope (JEOL JSM-5410LV) with an energy-dispersion spectrometer (JED-2140) at Kurashiki University of Science and the Arts.

The infrared (IR) spectrum of the anisotropic garnet was recorded with a PerkinElmer System 2000 FT-IR spectrophotometer at Okayama University of Science in the range of wave number from $4000 \mathrm{~cm}^{-1}$ to $400 \mathrm{~cm}^{-1}$, adopting the $\mathrm{KBr}$ matrix method in the room condition. The garnet sample was ground to a fine powder and then dispersed in a matrix of dry $\mathrm{KBr}$. The resolution of wave number is $2 \mathrm{~cm}^{-1}$.
Single crystal $\mathrm{X}$-ray diffraction data were obtained using a Rigaku AFC-7R automated 4-circle diffractometer with graphite-monochromatized $\mathrm{MoK} \alpha$ radiation $(\lambda=$ $0.71073 \AA$ ) from a rotating anode $(50 \mathrm{kV}, 200 \mathrm{~mA})$ at the National Museum of Nature and Science. A small awkward flattened fragment with approximate dimensions of $0.12 \times 0.10 \times 0.03 \mathrm{~mm}^{3}$ was picked from the thin section used for the electron-microprobe analysis. Data were measured in a hemisphere of the reciprocal space $\left(5^{\circ}<2 \theta\right.$ $<65^{\circ}$ ) for the analysis in the triclinic system. Data in a part of the other hemisphere $\left(10^{\circ}<2 \theta<30^{\circ}\right)$ were also measured to calculate the $R_{\text {int. }}$ The extinction $h+k+l=$ $2 n$ for $h k l$ was confirmed and applied for the measurement, whereas the other extinctions, $k=2 n$ and $l=2 n$ for $0 k l$, and $2 h+l=4 n$ for $h h l$, were not adopted in the measurement to reconfirm the extinctions in detail. Data reduction to $F_{\mathrm{o}}^{2}$ with Lorentz and polarization corrections and correction for absorption ( $\psi$-scan procedure) were carried out with a computer program by Dr. Kazumasa Sugiyama of the Tohoku University (personal communication, 2000). The SHELXL-97 software package (Sheldrick, 2008) was employed to refine the crystal structure. The scattering factors for the neutral atoms and anomalous dispersion factors were taken from the International Tables for X-ray Crystallography, Volume C (1992). The fractional atom coordinates of oxygen atom determined by Lager et al. (1989) were adopted as the initial model with cubic symmetry $(I a \overline{3} d)$ for the present refinements. Full-matrix least-squares refinement was performed by refining the positional parameters, scale factor, and displacement parameters. The occupancy parameters of $\mathrm{Ca}$, $\mathrm{Si}$ and $\mathrm{O}$ were fixed to 1 ignoring the substitution of $\mathrm{Fe}$ for $\mathrm{Ca}$, whereas that of $\mathrm{Al}$ for $\mathrm{Fe}$ in the octahedral $M$ site were refined with the constraint of $\mathrm{Al}+\mathrm{Fe}=1$, during the refinement in the cubic space group $I a \overline{3} d$. Then in the calculation in triclinic symmetry ( $I \overline{1})$, the occupancy parameter for each $\mathrm{Ca}$ site was refined with the constraint of $\mathrm{Ca}$ $+\mathrm{Fe}=1$, in addition to each $M$ site where $\mathrm{Al}+\mathrm{Fe}=1$.

\section{RESULT}

\section{Optical properties}

As an example, thin sections nearly parallel to (110) and (100) of the anisotropic garnet from Yamansu ore deposit are shown in Figure 3. A thin section of the former shows lamellar texture similar to albite twin in plagioclase. The optical birefringence of the garnet is up to 0.002 (Fig. 3A). The optical birefringence of later (Fig. 3B), which shows spotty or undulatory extinction, is from 0.001 to 0.004 . Most of the garnets are shown oscillatory, spotty or undulatory extinction, and contained cracks and inclu- 

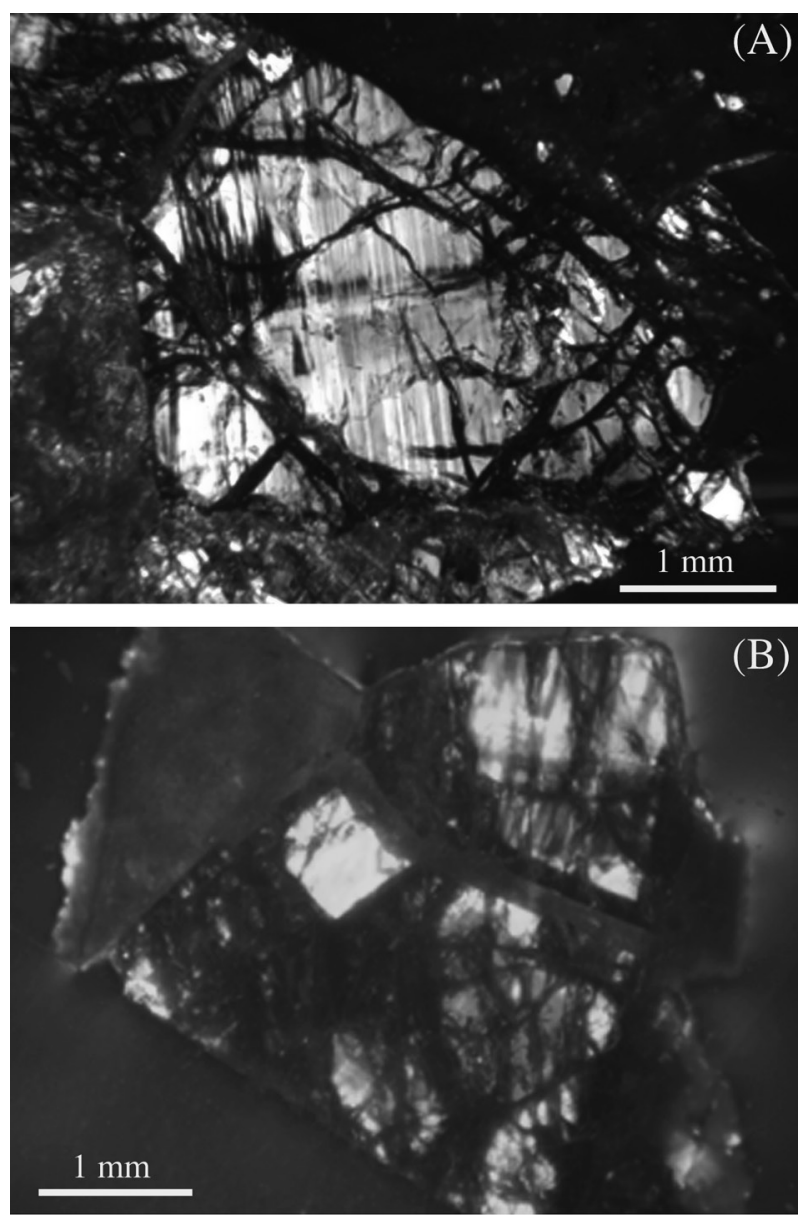

Figure 3. Photomicrographs taken with crossed polarizers. (A) Parallel to near (110), and (B) (100) of an anisotropic garnet.

sions (Fig. 3). These irregularities preclude accurate determination of the orientation of optic axes and $2 \mathrm{~V}$ angles. Thus, the optical birefringence represents not the true value but an apparent and approximate birefringence.

\section{Chemistry}

Composition image (back-scattered electron image), micrograph of cross-polarized light, and X-ray images of element distribution map in the garnet from the Yamansu ore deposit are shown in Figure 4. It is slightly observed that there is a negative correlation between $\mathrm{Al}$ and $\mathrm{Fe}$ contents (Figs. 4C and 4I), but no correlation with interference pattern of the cross-polarized light (Fig. 4B). The garnet (Fig. 3A) could be divided into significantly and weakly anisotropic parts based on the observation under a microscope, of which the former part was used for the crystallographic and IR absorption studies. The results of electron microprobe analyses of the significantly and weakly anisotropic parts in the Yamansu garnet are shown in Table 1 for comparison. $\mathrm{FeO}$ obtained by electron mi-
Table 1. Chemical compositions of the significantly and weakly anisotropic parts in the garnet from the Yamansu ore deposit, Xinjiang, China

\begin{tabular}{|c|c|c|c|c|c|c|}
\hline \multirow[b]{2}{*}{$(w t \%)$} & \multicolumn{3}{|c|}{1} & \multicolumn{3}{|c|}{2} \\
\hline & $\mathrm{n}^{*}=10$ & Range & SD & $\mathrm{n}^{*}=7$ & Range & SD \\
\hline$\overline{\mathrm{SiO}_{2}}$ & 37.82 & $37.15-38.03$ & 0.26 & 37.14 & $36.92-37.34$ & 0.11 \\
\hline $\mathrm{TiO}_{2}$ & 0.15 & $0.00-0.49$ & 0.16 & 0.09 & $0.00-0.23$ & 0.09 \\
\hline $\mathrm{Al}_{2} \mathrm{O}_{3}$ & 11.81 & $9.58-12.54$ & 0.90 & 9.15 & $8.30-10.38$ & 0.64 \\
\hline $\mathrm{Cr}_{2} \mathrm{O}_{3}$ & 0.18 & $0.00-0.58$ & 0.21 & 0.07 & $0.00-0.28$ & 0.10 \\
\hline $\mathrm{Fe}_{2} \mathrm{O}_{3}{ }^{* *}$ & 14.60 & $12.91-17.49$ & 1.22 & 18.39 & $16.47-19.65$ & 0.96 \\
\hline $\mathrm{FeO}^{* *}$ & 1.21 & $0.99-2.08$ & 0.40 & 1.42 & $0.44-2.48$ & 0.63 \\
\hline $\mathrm{MnO}$ & 0.68 & $0.50-0.80$ & 0.15 & 0.38 & $0.02-0.90$ & 0.30 \\
\hline $\mathrm{MgO}$ & 0.20 & $0.00-0.41$ & 0.12 & 0.13 & $0.02-0.18$ & 0.09 \\
\hline $\mathrm{CaO}$ & 33.27 & $32.51-33.77$ & 0.37 & 32.83 & $32.02-33.75$ & 0.50 \\
\hline $\mathrm{NiO}$ & 0.00 & & 0.00 & 0.10 & $0.00-0.34$ & 0.12 \\
\hline $\mathrm{Na}_{2} \mathrm{O}$ & 0.01 & $0.00-0.03$ & 0.01 & 0.05 & $0.00-0.16$ & 0.06 \\
\hline $\mathrm{K}_{2} \mathrm{O}$ & 0.00 & & 0.00 & 0.00 & & 0.00 \\
\hline Total & 99.93 & & & 99.75 & & \\
\hline
\end{tabular}

Formulae on the basis of $24 \mathrm{O}$ atoms

$\begin{array}{lll}\mathrm{Si} & 6.012 & 6.005\end{array}$

Ti $\quad 0.017 \quad 0.010$

$\mathrm{Al} \quad 2.213 \quad 1.744$

$\begin{array}{lll}\mathrm{Cr} & 0.023 & 0.008\end{array}$

$\mathrm{Fe}^{3+} \quad 1.747 \quad 2.238$

$\Sigma \quad 4.000 \quad 4.000$

$\mathrm{Fe}^{2+} \quad 0.161 \quad 0.192$

$\begin{array}{lll}\mathrm{Mn} & 0.091 & 0.051\end{array}$

$\mathrm{Mg} \quad 0.047 \quad 0.031$

$\begin{array}{lll}\mathrm{Ca} & 5.667 & 5.688\end{array}$

$\begin{array}{lll}\mathrm{Ni} & 0.000 & 0.013\end{array}$

$\begin{array}{lll}\mathrm{Na} & 0.003 & 0.016\end{array}$

$\begin{array}{lll}\mathrm{K} & 0.000 & 0.000\end{array}$

$\begin{array}{lll}\Sigma & 5.969 & 5.991\end{array}$

1. Significantly anisotropic part.

2. Weakly anisotropic part.

${ }^{*}$ The number of analyzed spots.

${ }^{* *}$ See text.

croprobe analyzer was converted to $\mathrm{FeO}+\mathrm{Fe}_{2} \mathrm{O}_{3}$ by assuming that the deficiency of $\mathrm{Ti}+\mathrm{Al}+\mathrm{Cr}$ available for the octahedral $M$ sites is made up by $\mathrm{Fe}^{3+}$. The chemical compositions are essentially in the ranges of the grossular (Grs)-andradite (And) solid solution with constituents of uvarovite (Uvt), pyrope (Prp), almandine (Alm) and spessartine (Sps). The average chemical compositions of the significantly and weakly anisotropic parts are $\mathrm{Grs}_{50.7} \mathrm{And}_{43.7}$ $\mathrm{Uvt}_{0.6} \operatorname{Prp}_{0.8} \mathrm{Alm}_{2.7} \mathrm{Sps}_{1.5}$ and $\mathrm{Grs}_{38.8} \mathrm{And}_{5.9} \mathrm{Uvt}_{0.2} \operatorname{Prp}_{0.5} \mathrm{Alm}_{3.2}$ $\mathrm{Sps}_{0.9}$, respectively. The significantly anisotropic part contains pyralspite molecule of $2.8 \%$ to $6.0 \%$, and uvarovite content is up to $1.8 \%$. On the other hand, pyralspite and uvarovite molecules of weakly anisotropic part are varied from $2.0 \%$ to $7.3 \%$, and up to $0.8 \%$, respectively. 


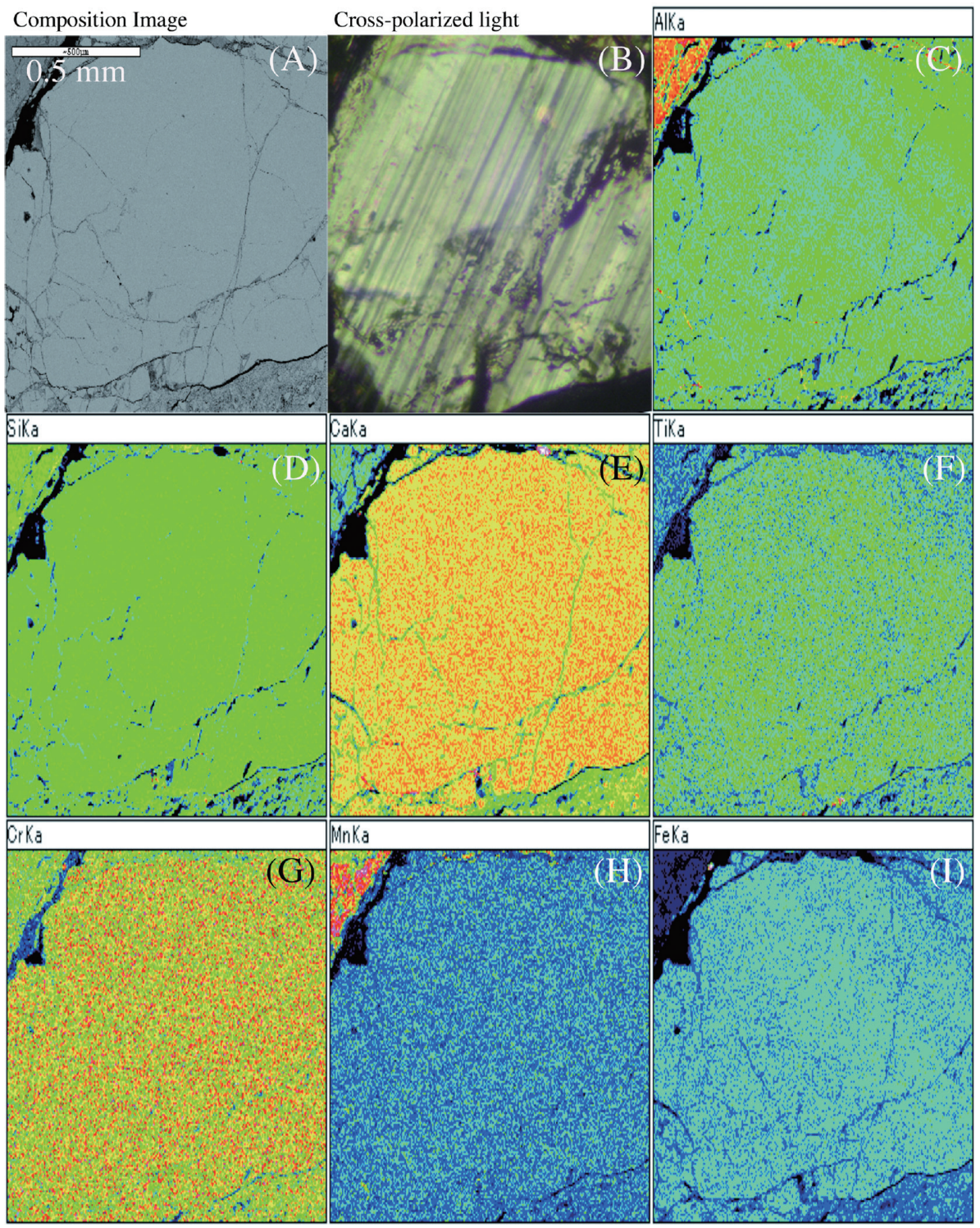

Figure 4. Composition image, micrograph of cross-polarized light, and $\mathrm{X}$-ray images of element distribution map in an anisotropic garnet from the Yamansu deposit. (A) composition image. (B) Cross-polarized light. (C) $\mathrm{Al} K \alpha$ image. (D) $\mathrm{Si} K \alpha$ image. (E) $\mathrm{CaK} \alpha$ image. (F) TiKa image. (G) $\mathrm{Cr} K \alpha$ image. (H) $\mathrm{MnK \alpha}$ image. (I) $\mathrm{Fe} K \alpha$ image.

The two parts with different degrees in optical anisotropy showed the difference in the $\mathrm{Fe}^{3+} /\left(\mathrm{Fe}^{3+}+\mathrm{Al}\right)$ molar ratio. The ratio of the significantly anisotropic part $(0.39-0.54)$ is lower than the weakly anisotropic one (0.50-0.60). Gaspar et al. (2008) reported that Fe-rich garnets were isotropic, whereas Al-rich garnets deviated from cubic symmetry and were anisotropic, in the association with garnets of chemical composition ranging from $\mathrm{And}_{30} \mathrm{Grs}_{70}$ to almost pure andradite $\left(\mathrm{And}_{>99}\right)$ from the Crown Jewel Au-skarn deposit. On the other hand, Shtukenberg et al. (2001) mentioned that the birefringences of 13 crystals having $\mathrm{Fe} /(\mathrm{Fe}+\mathrm{Al})$ ratios from $13 \%$ to $49 \%$ are usually constant. Although the Yamansu garnet showed chemistry conformity with the trend of Gaspar et al. (2008), the degree of birefringence should be addressed rather to the nature of the symmetry reduction than to the pure crystal chemistry, as pointed out for a

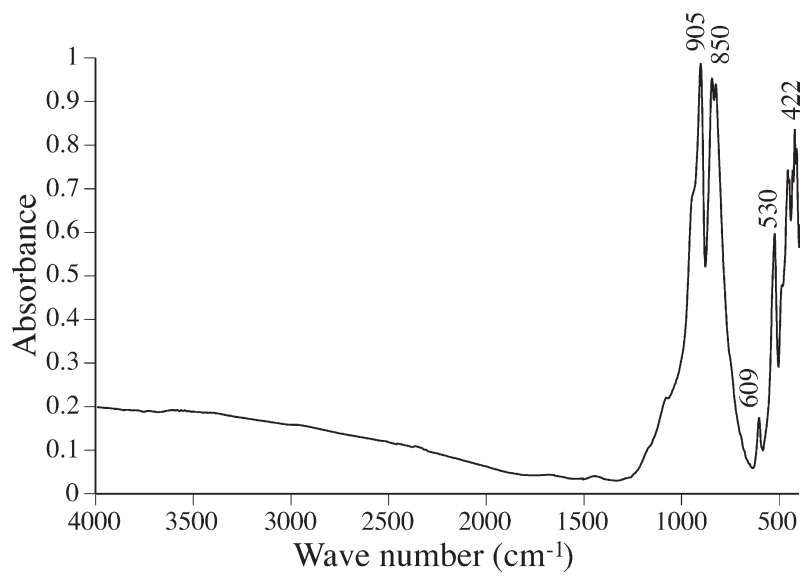

Figure 5. FT-IR spectrum of an anisotropic garnet from the Yamansu deposit. Measurement region is between $400 \mathrm{~cm}^{-1}$ and $4000 \mathrm{~cm}^{-1}$. 
number of crystals with similar compositions having different crystal structures by Shtukenberg et al. (2005).

\section{IR absorption}

FT-IR spectra of the garnet from the Yamansu deposit are shown in Figure 5. The spectrum showed numerous absorption bands in the region 905-422 $\mathrm{cm}^{-1}$, which were stretching vibration and bending motion of the $\left[\mathrm{SiO}_{4}\right]$ tetrahedral. However, no absorption band of $\left[(\mathrm{OH})_{4}\right]$ substituting the tetrahedral $\left[\mathrm{SiO}_{4}\right]$ was observed in the region between $3700 \mathrm{~cm}^{-1}$ and $3500 \mathrm{~cm}^{-1}$. This is a typical difference from a $\left[(\mathrm{OH})_{4}\right]$-bearing andradite from the Totalp serpentinite and a hydrogrossular sample from South Africa (Peters, 1965) showing O-H stretching absorption bands at around $3600 \mathrm{~cm}^{-1}$. Harmon et al. (1982) has stated that the $\mathrm{OH}$ stretching band of silica free garnet spans from $3750 \mathrm{~cm}^{-1}$ to about $2000 \mathrm{~cm}^{-1}$, and that the integrated intensity of the $\mathrm{OH}$ stretching absorption in garnet is of a magnitude consonant with the presence of hydrogen bonding. Consequently, the anisotropic garnet from Yamansu contains no detectable $\mathrm{OH}$ because the IR spec-

Table 2. Crystallographic data and experimental conditions of the refinement of crystal structure of the anisotropic garnet

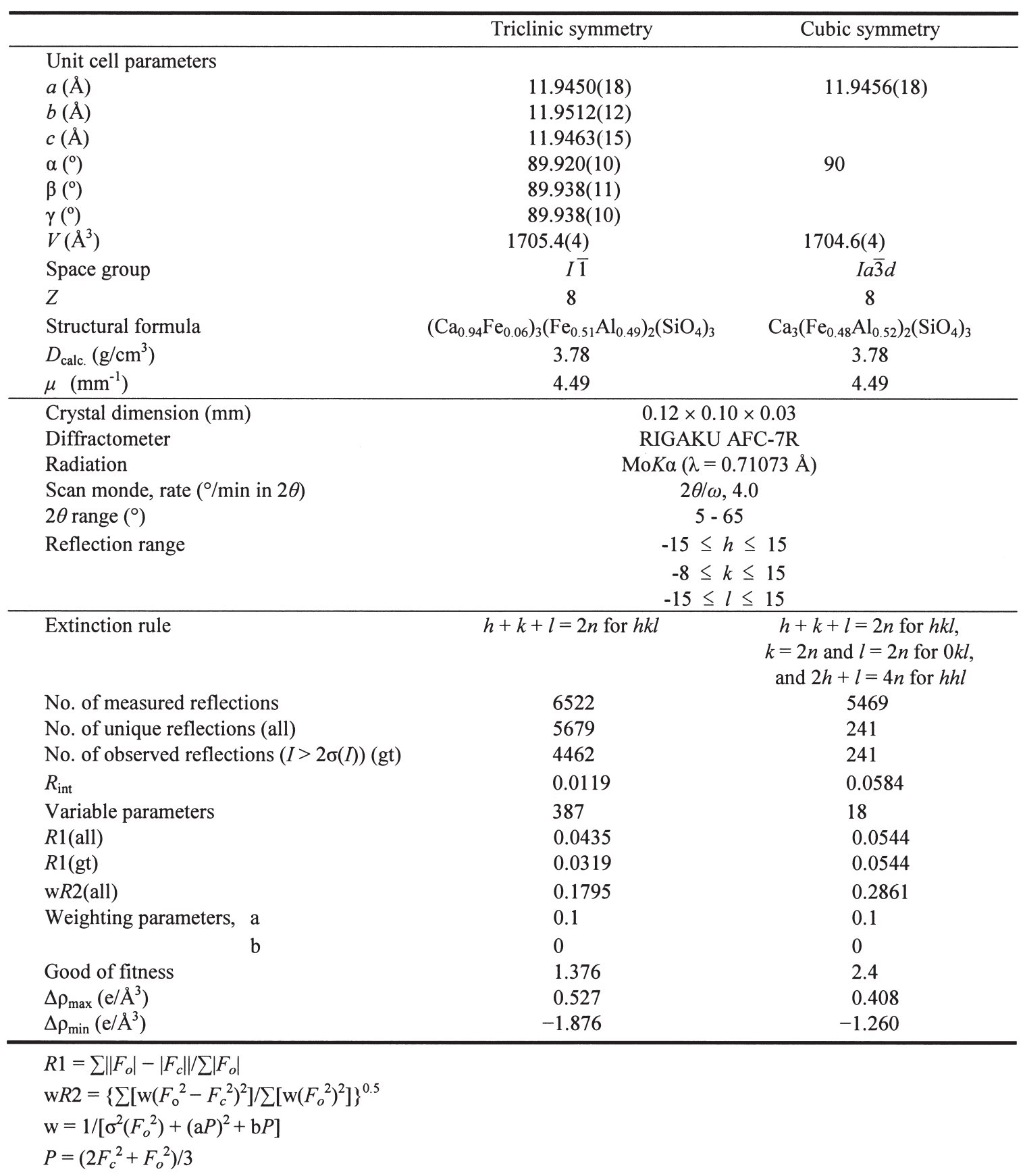




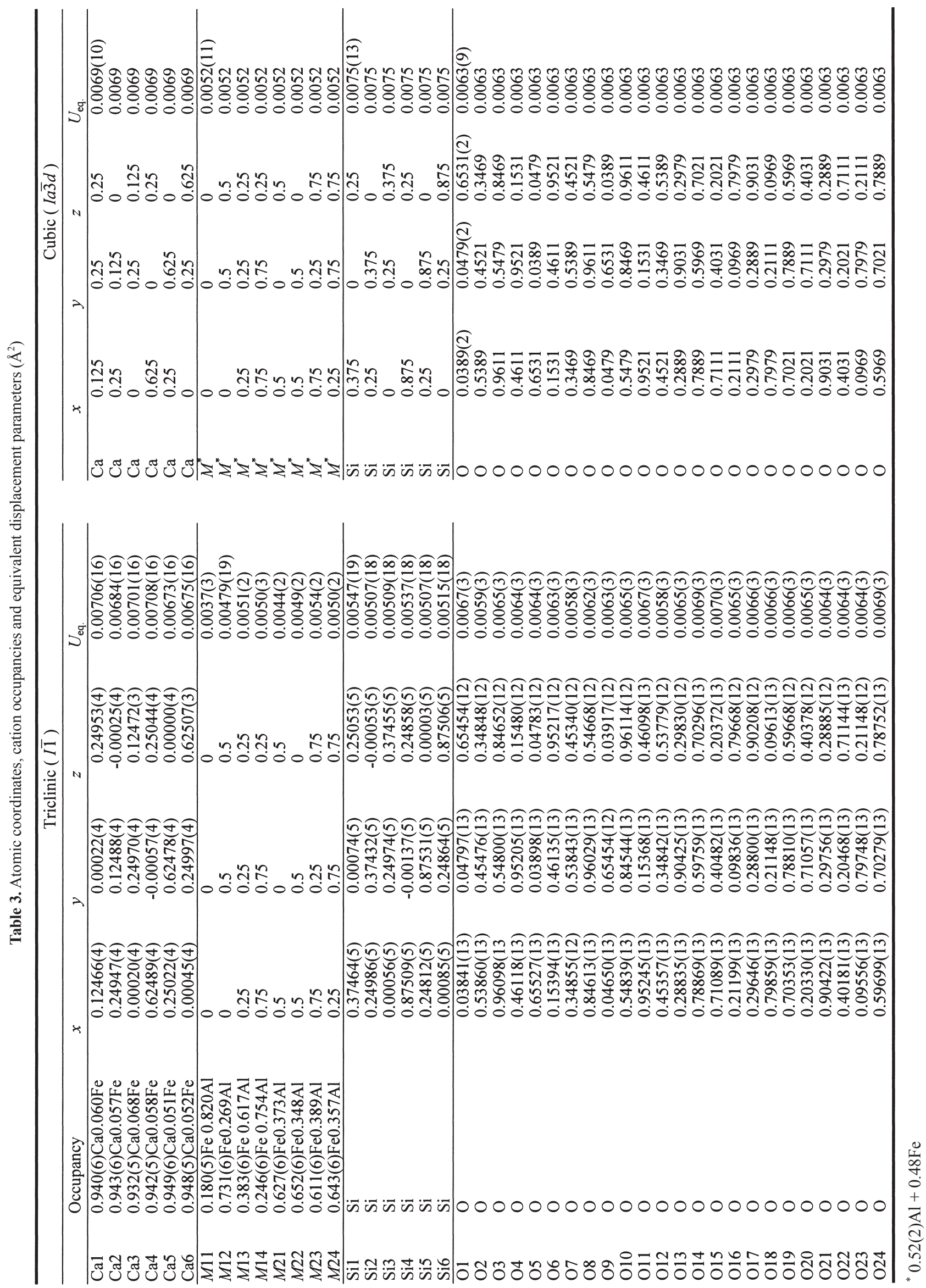


trum has no absorption band, and between $3750 \mathrm{~cm}^{-1}$ and $2000 \mathrm{~cm}^{-1}$ due to the $\mathrm{OH}$ stretching band by hydrogen bonding.

\section{Refinement of crystal structure}

Although some of 6522 reflections, such as $013,222,033$ and 114, were observed against the extinctions, they were ignorable weak and were rejected in the refinement with the cubic structural model. A preliminary refinement with cubic symmetry of $I a \overline{3} d$ converged with final $R 1=0.0544$ using 241 independent reflections $\left(R_{\text {int }}=0.0584\right)$, which were merged from the reflections in the hemisphere of the reciprocal space. A further refinement with full-matrix re- finement on $F^{2}$ of 5679 independent reflections $\left(R_{\text {int }}=\right.$ $0.0119)$, of which 4462 had criteria to be larger than $2 \sigma(I)$, was attempted as triclinic system of $I \overline{1}$ to yielded $R 1=$ 0.0435 and $\mathrm{w} R 2=0.1795$. The result of the refinement was summarized in Table 2. The final atomic coordinates, cation occupancies and equivalent displacement parameters of refinement with the triclinic symmetry were given in Table 3 together with those of the cubic symmetry explicated by the symmetry operations for comparison. Selected interatomic distances are summarized in Table 4. The cif files including the anisotropic displacement parameters and the $F_{\mathrm{o}}-F_{\mathrm{c}}$ table are available online from http://japanlinkcenter.org/DN/JST.JSTAGE/jmps/120927.

The refinement showed no significant drifts of atoms

Table 4. Selected interatomic distances (in $\AA$ ) in the crystal structure of the anisotropic garnet

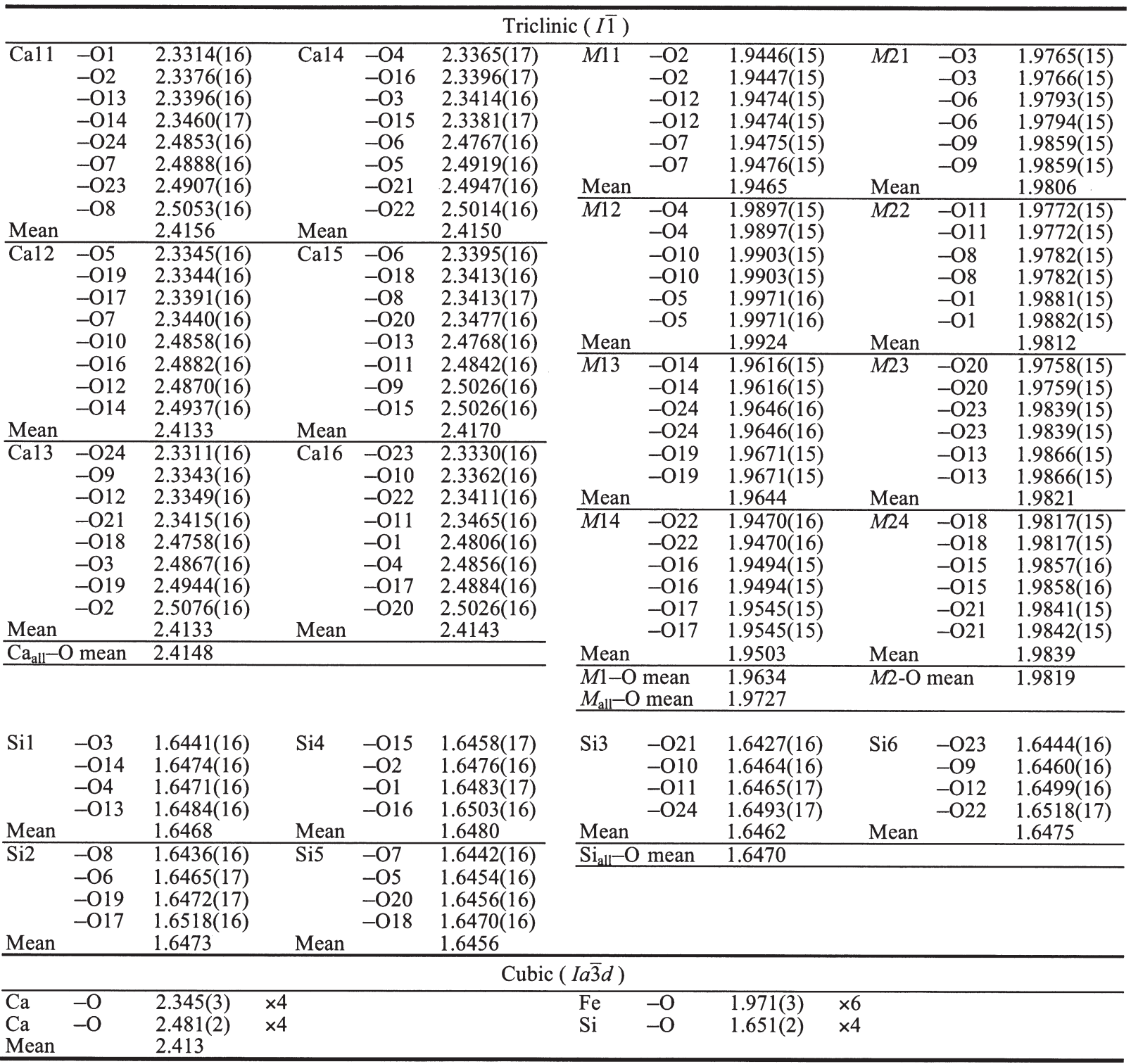

The data of preliminary refinement with cubic symmetry $(I a \overline{3} d)$ are given for comparison. 


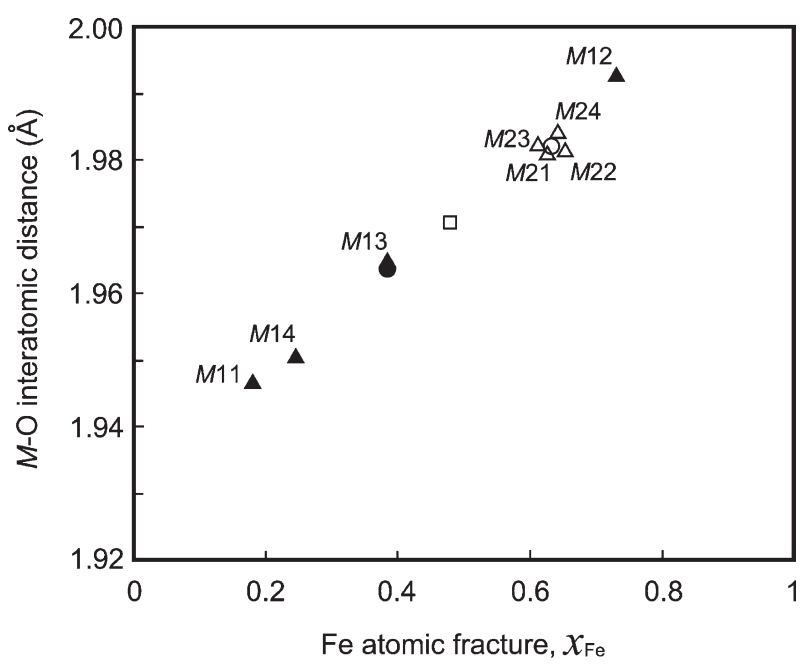

Figure 6. The $M-\mathrm{O}$ bond distances versus the $M$ site occupancies by Fe. Data for the cubic (square), orthorhombic (circles) and triclinic (triangles) crystal structures.

from the ideal positions corresponding to the atomic positions in the cubic symmetry. The variation in occupancy parameters of $\mathrm{Fe}$ and $\mathrm{Al}$ indicated the $\mathrm{Fe}-\mathrm{Al}$ ordering in the 8 octahedral $M$ sites, whereas the $\mathrm{Ca}-\mathrm{Fe}$ ordering in the 6 dodecahedral sites was negligible small (Table 3). Shtukenberg et al. (2005) pointed out that the mean $M-\mathrm{O}$ bond lengths linearly correlate with $\mathrm{Fe} /(\mathrm{Fe}+\mathrm{Al})$ proportions. This correlation corresponds to the differences in the electron density and ionic radius between $\mathrm{Al}$ and $\mathrm{Fe}$. The results of present refinement of crystal structure of Yamansu garnet exactly showed the linear correlation (Fig. 6) indicating the reasonability of the refinement of occupancy parameters.

Figure 6 apparently shows the ordering feature of $\mathrm{Fe}$ and $\mathrm{Al}$ in the octahedral $M$ sites. The $\mathrm{Fe}$ and $\mathrm{Al}$ atoms order with wide range variation among one of the two quartets of $M$ octahedra, $M 11-14$, whereas the occupancy proportions are almost constant, 0.65 among the other quartets, $M 21-M 24$. The calculated degree of ordering $m$ $=\left(x_{\mathrm{Oct} 1}-x_{\mathrm{Oct} 2}\right) /\left(x_{\mathrm{Oct} 1}+x_{\mathrm{Oct} 2}\right)$, the intersite distribution coefficient $K_{1-2}=x_{\mathrm{Oct} 2} /\left(1-x_{\mathrm{Oct} 2}\right) \cdot\left(1-x_{\mathrm{Oct} 1}\right) / x_{\mathrm{Oct} 1}$, and the degree of triclinicity $\xi=\left(\Delta M_{11-14}, \Delta M_{21-24}\right)_{\max } /\left(x_{\mathrm{Oct} 1}-x_{\mathrm{Oct} 2}\right)$ (Shtukenberg et al., 2005) were estimated as 0.244, 2.76, and 2.220, respectively, based on the present results of the Yamansu anisotropic garnet. The $\xi$ value 2.220 much greater than 1, the criteria for triclinic against to the pseudo-orthorhombic (Shtukenberg et al., 2005), means that the differences within the quartets is larger than the difference between two quartets, the $M 1$ and $M 2$, and indicates the crystal system of Yamansu anisotropic garnet to be triclinic.

\section{DISCUSSION}

The absence of substitution of $\left[(\mathrm{OH})_{4}\right]$ for $\left[\mathrm{SiO}_{4}\right]$ indicated by the IR absorption spectrum supports the result of crystal structure refinement revealing that the major cause of birefringence of the anisotropic garnet from the Yamansu deposit is the ordering of $\mathrm{Al}$ and $\mathrm{Fe}^{3+}$ in the octahedral $M$ site. The degree of ordering is not in the range of orthorhombic, but is beyond the range of pseudo-orthorhombic, conclusively within the range of triclinic symmetry. Griffen et al. (1992) represented that a group theoretical analysis based on the Landau formalism and including the theory of induced representations shows that the observed space group could have arisen by phase transformation from a parent cubic garnet (space group $I a \overline{3} d$ ), driven by a single order parameter in each case. Such transitions may occur (1) by the $\mathrm{T}_{2 \mathrm{~g}}$ irreducible representation, leading to possible space groups $R \overline{3} c, F d d d$, $C 2 / c$, or $I \overline{1} ;$ (2) by the $\mathrm{T}_{1 \mathrm{~g}}$ irreducible representation, leading to possible space groups $R \overline{3}, I 4_{1} / a, C 2 / c$, or $I \overline{1}$; or (3) by the $\mathrm{E}_{\mathrm{g}}$ irreducible representation, leading to possible space groups $I 4_{1} / a c d$ or $I b c a$. The first two ordering paths of $T_{2 g}$ and $T_{1 g}$ yield octahedral ordering; if the sizes of the octahedral cations are similar (as with $\mathrm{Al}$ and $\mathrm{Fe}^{3+}$ in grossular - andradite series garnets), ordering occurs by $\mathrm{T}_{2 \mathrm{~g}}$, and if they are different (as with $\mathrm{Mg}$ and $\mathrm{Mn}^{2+}$ in $\mathrm{Mg}$ $\mathrm{SiO}_{3}-\mathrm{MnSiO}_{3}$ series garnets), ordering occurs by $\mathrm{T}_{1 \mathrm{~g}}$. Garnets that possess cations ordered in the eightfold-coordinated sites (for example, some with both significant pyralspite and grossular components) order by $\mathrm{E}_{\mathrm{g}}$. Therefore, a major cause of birefringence of the garnet from the Yamansu deposit is transition of $T_{2 g}$ type. Namely, it is considered that the $\mathrm{T}_{2 \mathrm{~g}}$ garnet led to possible space group $I \overline{1}$ of triclinic system.

On the other hand, Hofmeister et al. (1998) proposed a cause of low birefringence and undulatory extinction to be affected by strain. The garnet from the Yamansu deposit often shows undulatory extinction and low birefringence (Fig. 3b). It is also possible that the garnet resulted from strain during and/or after crystallization (growth) as another cause of birefringence because the East Tianshan including the Yamansu is defined as that region north of the Middle Tianshan and south of the Tuha basin, and consists of the Tousuquan-Dananhu island arc, Kanggurtag suture zone, and Aqishan-Yamansu rift basin, which are separated by several large regional faults such as Aqikekuduke and Kanggur faults (Mao et al., 2005).

\section{ACKNOWLEDGMENTS}

We sincerely thank Dr. P. Wang of Chinese Academy of Geological Sciences and Dr. Lai Yong of Peking Univer- 
sity for assistance during the fieldwork. We thank two anonymous reviewers for their insightful and constructive comments. We also wish to thank the Research Instruments Centre of Okayama University of Science for the use of their facilities. This work was supported by a Grant-in-Aid for the Science Research (Nos. 17404025 and 24540522) sponsored by the Ministry of Education, Vulture, Sports, Science and Technology, Japan.

\section{DEPOSITORY MATERIALS}

Depository items (cif file and $F_{\mathrm{o}}-F_{\mathrm{c}}$ table) are available online from http://japanlinkcenter.org/DN/JST.JSTAGE/ jmps/120927.

\section{REFERENCES}

Akizuki, M. (1984) Origin of optical- variations in grossular- andradite garnet. American Mineralogist, 69, 328-338.

Allen, F.M. and Buseck, P.R. (1988) XRD, FTIR, and TEM studies of optically anisotropic grossular garnets. American Mineralogist, 73, 568-584.

Blanc, Y. and Maisonneuve, J. (1973) Sur la Biréfringence des grenats calciques. Bulletin de la Société francaise de Minéralogie et de Cristallographie, 96, 320-321.

Chase, A.B. and Lefever, R.A. (1960) Birefringence of synthetic garnets. American Mineralogist, 45, 1126-1129.

Deer, W.A., Howie, R.A. and Zussman, J. (1982) Rock Forming Minerals, vol. 1A: Orthosilicates, Longmans, London.

Gaspar, M., Knaack, C., Meinert, L.D. and Moretti, R. (2008) REE in skarn systems: A LA-ICP-MS study of garnets from the Crown Jewel gold deposit. Geochimica et Cosmochimica Acta, 72, 185-205.

Griffen, D.T., Hatch, D.M., Phillips, W.R. and Kulaksiz, S. (1992) Crystal chemistry and symmetry of a birefringent tetragonal pyralspite $_{75}$ - randite 24 garnet. American Mineralogist, 77, 399-406.

Harmon, K.M., Gabriele, J.M. and Nuttall, A.S. (1982) Hydrogen bonding. Journal of Molecular Structure, 82, 231-219.

International Tables for Crystallography, Volume C (1992) Wilson A.J.C. Ed., pp. 883, Kluwer Academic Publishers, Dordrecht.

Hofmeister, A.M., Schaal, R.B., Campbell, K.R., Berry, S.L. and Fagan, T.J. (1998) Prevalence and origin of birefringence in 48 garnets from the pyrope- almandine- grossularite- spes- $^{-}$ sartine quaternary. American Mineralogist, 83, 1293-1301.
Ingerson, E. and Barksdale, J.D. (1943) Iridescent garnet from the Adelaide Mining District, Nevada. American Mineralogist, 28, 303-312.

Kerr, P.F. (1977) Optical Mineralogy, pp. 492, McGraw-Hill, New York.

Kingma, K.J. and Downs, J.W. (1989) Crystal-structure analysis of a birefringent andradite. American Mineralogist, 74, 13071316.

Kitamura, K. and Komatsu, H. (1978) Optical anisotropy associated with growth striation of yttrium garnet, $\mathrm{Y}_{3}(\mathrm{Al}, \mathrm{Fe})_{5} \mathrm{O}_{12}$. Kristallographie und Technik. 13, 811-816.

Lager, G.A., Armbruster, T., Rotella, F.J. and Rossman, G.R. (1989) OH substitution in garnets: X-ray and neutron diffraction, infrared, and geometric-modelings tudies. American Mineralogist, 74, 840-851.

Lessing, P. and Standish, P.R. (1973) Zoned garnet from Crested Butte, Colorado. American Mineralogist, 58, 840-842.

Mao, J., Goldfarb, R.J., Wang, Y., Hart, C.J., Wang, Z. and Yang, J. (2005) Late Paleozoic base and precious metal deposits, east Tianshan, Xinjiang, China: Characteristics and geodynamic setting. Episodes, 28, 23-36.

Peters, T. (1965) A water-bearing andradite from the Totalp serpentine (Davos, Switzerland). American Mineralogist, 50, 1482-1486.

Rossman, G.R. and Aines, R.D. (1986) Spectroscopy of a birefringent grossular from Asbestos, Quebec, Canada. American Mineralogist, 71, 779-780.

Sheldrick, G.M. (2008) A short history of SHELX. Acta Crystallographica, A, 64, 112-122.

Shtukenberg, A.G., Punin, Yu. O., Frank-Kamenetskaya, O.V., Kovalev, O.G. and Sokolov, P.B. (2001) On the origin of anomalous birefringence in grandite garnets. Mineralogical Magazine, 65, 445-459.

Shtukenberg, A.G., Popov, D.Yu. and Punin, Yu.O. (2002) An application of the point-dipole model to the problem of optical anomalies in grandite garnets. Mineralogical Magazine, 66, 275-286.

Shtukenberg, A.G., Popov, D.Yu. and Punin, Yu.O. (2005) Growth ordering and anomalous birefringence in ugrandite garnets. Mineralogical Magazine, 69, 537-550.

Takéuchi, Y., Haga, N., Umizu, S. and Sato, G. (1982) The derivative structure of silicate garnets in grandite. Zeitschrift für Kristallographie, 158, 53-99.

Manuscript received September 27, 2012

Manuscript accepted May 10, 2013

Published online September 4, 2013

Manuscript handled by Norimasa Shimobayashi 